\title{
1 Quantitative trait loci associated with natural diversity in water-use efficiency and
}

2 response to soil drying in Brachypodium distachyon

4 David L. Des Marais ${ }^{\mathrm{a}, \mathrm{b}}$, Samsad Razzaque ${ }^{\mathrm{a}}$, Kyle M. Hernandez ${ }^{\mathrm{a}, \mathrm{c}}$, David F. Garvin ${ }^{\mathrm{d}}$ and Thomas 5 E. Juenger ${ }^{\mathrm{a}}$

7 a.. Department of Integrative Biology and Institute for Cell and Molecular Biology, The

8 University of Texas at Austin

9 b. Present address: Arnold Arboretum and Department of Organismic and Evolutionary Biology,

10 Harvard University, Cambridge, MA

11 c. Present address: Center for Research Informatics, The University of Chicago, Chicago, IL

12 d. U.S. Department of Agriculture - Agricultural Research Service, Plant Science Research Unit, 13 St. Paul, MN

14

15 Author for correspondence:

16 David L. Des Marais

171300 Centre St.

18 Roslindale, MA 02131 U.S.A.

19 Tel: +01 617-384-5495

20 Email: desmarais@,fas.harvard.edu 


\section{Abstract}

23 All plants must optimize their growth with finite resources. Water use efficiency (WUE)

24 measures the relationship between biomass acquisition and transpired water. In the present

25 study, we performed two experiments to understand the genetic basis of WUE and other

26 parameters of plant-water interaction under control and water-limited conditions. Our study used

27 two inbred natural accessions of Brachypodium distachyon, a model grass species with close

28 phylogenetic affinity to temperate forage and cereal crops. First, we identify the soil water

29 content which causes a reduction in leaf relative water content and an increase in WUE. Second,

30 we present results from a large phenotyping experiment utilizing a recombinant inbred line

31 mapping population derived from these same two natural accessions. We identify QTLs

32 associated with environmentally-insensitive genetic variation in WUE, including a pair of

33 epistatically interacting loci. We also identify QTLs associated with constitutive differences in

34 biomass and a QTL describing an environmentally-sensitive difference in leaf carbon content.

35 Finally, we present a new linkage map for this mapping population based on new SNP markers

36 as well as updated genomic positions for previously described markers. Our studies provide an

37 initial characterization of plant-water relations in B. distachyon and identify candidate genomic

38 regions involved in WUE.

\section{Keywords}

41 Water Use Efficiency, GxE, QTL mapping, epistasis, abiotic stress, Brachypodium distachyon

\section{1. Introduction}

44 The interaction between plants and water is a critical determinant of agricultural productivity,

45 species distribution, and ecological community assembly [1-3]. Water use efficiency (WUE)

46 broadly describes the ratio of carbon acquired via photosynthesis to the amount of water

47 transpired. As such, WUE reflects a key trade-off in plant growth strategy; plants may fix

48 carbon at the biophysical limit of their photosynthetic machinery, but doing so will deplete

49 water, a potentially finite environmental resource. Given this functional trade-off and the

50 considerable variation in soil water availability and atmospheric evaporative demand of natural 
51 settings, it is perhaps unsurprising that diverse species of plants - and many populations within 52 species - display substantial variation in WUE (e.g. [4-11]).

Because WUE is a ratio, variation in either the numerator - carbon assimilation - or the denominator - water consumption -- can lead to WUE variation between plants or in response to environmental cues such as soil water availability. WUE can be measured in several ways [12]. Most broadly, the parameter of greatest ecological and agricultural interest is the total biomass or yield acquired per water consumed over the lifetime of a plant, termed Transpiration Efficiency, or TE [13]. However, measuring TE accurately is challenging and so several related parameters and their analytical proxies are more commonly reported and used as breeding targets. Instantaneous WUE is the leaf-level rate of carbon fixation expressed as a function of water transpired and, as such, reflects short-term physiological processes. Integrated WUE, measuring the cumulative effect of leaf-level processes over the lifetime of a measured tissue, is closely approximated by the ratio of two isotopes of carbon, ${ }^{13} \mathrm{C}$ and ${ }^{12} \mathrm{C}[14]$. Abundant evidence from multiple plant species under a wide range of conditions has shown that ${ }^{13} \mathrm{C}$ ratios - measured either as discrimination, $\Delta^{13} \mathrm{C}$, or composition, $\delta^{13} \mathrm{C}$-- are a good approximation of integrated WUE for plants employing C3 photosynthesis [15]. Physiologically, the relationship between ${ }^{13} \mathrm{C}$, ${ }^{12} \mathrm{C}$, and WUE is due primarily to the preference for Rubisco to fix ${ }^{12} \mathrm{C}$, and generally accepting ${ }^{13} \mathrm{C}$ more frequently when its molar ratio is elevated by partial stomatal closure and thus reduced stomatal conductance. $\Delta^{13} \mathrm{C}$ and $\delta^{13} \mathrm{C}$ therefore reflect the amount of carbon fixed when stomata are relatively more closed, which closely tracks WUE (and TE) in C3 plants. In the present study, we focus on $\delta^{13} \mathrm{C}$ as a proxy for integrated lifetime WUE.

WUE is a complex trait because environmental, genetic, and developmental factors lead

74 basis of WUE has been studied in several plant systems, with a general theme emerging that 75 multiple genetic variants of small to moderate effect drive WUE differences among natural 76 populations and among agricultural varieties of plants (e.g. [4, 16, 19-26]). In some cases, 77 specific molecular variants affecting WUE have been identified; these findings reinforce the notion that genes of diverse function can drive differences in WUE. In Arabidopsis thaliana, the molecular basis of natural variation in WUE has been identified for three loci. These include both highly pleiotropic mutations in FRIGIDA [27] and ERECTA [28] affecting multiple whole-

81 plant traits, as well as a WUE-reducing nucleotide variant in a MAP kinase (AtMPK12) whose 
82 apparent phenotypic effects are limited to guard cell development and environmental response 83 [29]. Among these, AtMPK12 and FRI largely exert their effects on WUE via altered stomatal 84 conductance whereas ERECTA affects both stomatal conductance and carbon assimilation.

Due to the strong relationship between WUE and plant performance in the field $[5,11]$, both the genetic and physiological basis of WUE and TE in crop species are of considerable interest $[13,30,31]$. Using $\Delta^{13} \mathrm{C}$ to breed for high TE has been particularly successful in rainfed Mediterranean-type agricultural settings where most precipitation occurs prior to the growing season. Reasoning that varieties which acquire more biomass per unit water consumed (high TE) should generate relatively higher yield under dry conditions than more profligate varieties, Rebetzke and colleagues [32] successfully used $\Delta^{13} \mathrm{C}$ as a target of selection to increase the TE of wheat varieties and thereby realized a yield gain in water-limited environments. The yield advantage of these high-TE varieties became less pronounced as compared to traditional varieties as rainfall increased. Ecologically, the cause of this trade-off appears to be that high-TE plants grow more slowly, effectively preserving moisture stored in the soil for later in the season. When available soil water is not limiting, low-TE varieties have an advantage. It is not known which aspect of increased WUE -- altered stomatal conductance or photosynthetic capacity - was targeted during this breeding process, nor is the molecular control of variation in natural variation in WUE known in any grass system. In the present study, we extend this important area of research to a model genetic system which affords the opportunity to understand the genetic basis of the trade-offs that plants experience in coordinating resource use during growth 102 (e.g. [33]). southern Europe, north Africa, and the Middle East [34]. Abundant genetic and genomic resources are now available for $B$. distachyon, which has been developed as a model genetic system for temperate cereal crops in the Pooideae such as wheat, oat, and barley [35]. The high genomic synteny between $B$. distachyon and its Pooid relatives [36] facilitates the translation of gene discovery in B. distachyon to possible improvement of cereal crops. In the present study,

110 and $\mathrm{Bd} 3-1$, under two watering regimes. $\mathrm{Bd} 21$ was originally collected east of Mosul, in 111 northern Iraq, and was the genotype sequenced to produce a reference $B$. distachyon genome 112 sequence [36]. Bd3-1 was also originally collected in Iraq, although the exact details of its 
113 provenance are unknown [37]. A near-complete genome sequence is also available for Bd3-1

114 [38]. Both genotypes exhibit spring-annual life histories and do not require vernalization to

115 initiate the transition to flowering [39]. We first exposed $\mathrm{Bd} 21$ and $\mathrm{Bd} 3-1$ to a progressive soil

116 drying treatment in order to identify the reduction in soil water content that causes measurable

117 phenotypic change in plant traits. We then grew individuals from an existing Recombinant

118 Inbred Line (RIL; [40]) mapping population to identify regions of the genome that drive

119 constitutive differences between the two genotypes as well as regions associated with differences

120 in soil-drying response between them. Together, these studies provide the first characterization

121 of the genetic architecture and differentiation of $\mathrm{Bd} 21$ and $\mathrm{Bd} 3-1$ in terms of water relations and

122 responses to moderate soil drying.

\section{Methods}

\subsection{Assessing treatment response and genetic diversity}

126 We planted seeds of Bd21 and Bd3-1 in Deepot D16H pots (Stuewe \& Sons) filled with 250mL

127 of Profile porous ceramic rooting media (Profile Products). The dry weight (DW) of each pot

128 was recorded and then plants were saturated with a 1:50 dilution of Liquid Grow Plant Food

129 (Dyna-Gro). Pots were allowed to equilibrate to the field capacity (FC) of the soil overnight, and

130 then weighed again. We subtracted DW from FC weight to determine the water content of each

131 pot as the basis for the subsequent controlled soil dry down. Pots were then placed at $4^{\circ} \mathrm{C}$ for $7 \mathrm{~d}$

132 to synchronize seedling germination.

All plants were grown in a Percival AR-66 growth chamber initially set to $25^{\circ} \mathrm{C}$ days and

$13420^{\circ} \mathrm{C}$ nights. Plants were watered with tap water every other day and with water supplemented

135 with fertilizer, as above, every week. After 21 days of growth, we ramped the temperature up by

$13622^{\circ} \mathrm{C}$ every three hours to constant $33^{\circ} \mathrm{C}$ day and $25^{\circ} \mathrm{C}$ night conditions. This high temperature

137 was chosen because our prior work demonstrated that $\mathrm{Bd} 21$ and $\mathrm{Bd} 3-1$ plants have their highest

138 seed yield under well-watered conditions at $\sim 33^{\circ} \mathrm{C}$ (Des Marais et al. in review). On the $22^{\text {nd }}$

139 day of growth, we randomly assigned pots to control and drying treatments. Control plants were

140 watered to $85 \% \mathrm{FC}\left(0.54 \mathrm{~g} \mathrm{H}_{2} \mathrm{O} / \mathrm{g}\right.$ soil $)$ every morning while dry treatment plants were allowed

141 to dry down their pots over eight days. During the dry-down, dry treatment pots were daily

142 brought to specified water contents such that no plant experienced greater than $10 \%$ loss of field

143 capacity over a $24 \mathrm{hr}$ period. 
During the dry-down, every second day we harvested four randomly-selected individuals 145 of each genotype from each treatment (control and drying) for phenotyping. At harvest days 1

146 (70\% FC), $4(55 \% \mathrm{FC}), 6(45 \% \mathrm{FC})$, and $8(40 \% \mathrm{FC})$ we harvested a single leaf from each plant 147 and determined leaf Relative Water Content (RWC) as described previously [4]. Leaf relative 148 water content assesses the amount of water in a leaf as a function of the maximum water content 149 that a leaf can attain, i.e. its water content when turgid. On day 8 (30d post-germination), we 150 also harvested complete above- and below-ground tissue and dried these separately at $80^{\circ} \mathrm{C}$ for 151 two days. Dried tissue was weighed to determine above- and below-ground biomass, and their 152 ratio. Complete above-ground tissues were ground to a fine powder and analyzed for $\delta^{13} \mathrm{C}$, 153 carbon content, and nitrogen content using mass spectrometry at the University of Georgia 154 Analytical Chemistry Facility. Carbon isotope composition is reported relative to the PeeDee 155 Belemnite standard, and is used rather than carbon isotope discrimination $(\Delta)$ because the 156 isotopic composition of $\mathrm{CO}_{2}$ in the air varies periodically in the chambers and we are principally 157 interested in comparing relative values among samples in our experiment.

158 We modeled variation in leaf RWC using ANOVA with accession, treatment, harvest 159 date, and their interaction as fixed effects using JMP Pro 10.0 (SAS Institute, Inc.). The results 160 of this analysis indicated that our progressive soil dry-down resulted in significant reduction in 161 leaf RWC over time. We next modeled leaf RWC, $\delta^{13} \mathrm{C}$, above and below-ground biomass, and 162 leaf carbon and nitrogen content from the Day 8 harvest using ANOVA with two levels of 163 genotype (Bd21 and Bd3-1), two levels of treatment (Control, 85\% FC and Dry, 40\% FC), and 164 their interaction.

\subsection{New markers and an updated linkage map for the Bd3-1 x Bd21 RIL Population}

167 We exploited a previously-generated RIL population derived from a cross between Bd3-1 and $168 \mathrm{Bd} 21$ [40]. These accessions were chosen as parents because $\mathrm{Bd} 21$ was the accession used to 169 generate the reference genome [36] and because both accessions have been extensively 170 characterized phenotypically (e.g. [38-46]). Moreover, both accessions exhibit rapid-cycling 171 spring-annual life history strategies [39], thus reducing the time required to generate inbred lines.

172 Development of the RIL population and some of its characteristics were described previously 173 [40]. Individual plants representing each RIL were grown in soil in a Percival AR-66 growth 174 chamber with $25^{\circ} \mathrm{C}$ days and $20^{\circ} \mathrm{C}$ nights. Plants were watered with tap water every other day 
175 and with water supplemented with fertilizer, as above, every week. After 21 days of growth, leaf 176 tissue was harvested on liquid nitrogen and ground to a fine powder. We extracted total genomic DNA using the CTAB protocol of Kelly and Willis [47], and used the 2bRAD protocol of Wang

178 et al. [48] to identify new markers for the RIL population. In brief, this protocol uses restriction

179 enzymes to fractionate the genome into DNA fragments of known size and then incorporates

180 oligonucleotide adaptors for sequencing on the SOLiD system. Sequencing was done at the

181 University of Texas at Austin Genome Sequencing and Analysis Facility.

182 Raw SOLiD reads with low quality (average quality $<20)$ or homopolymers $(>20 \%$ of

183 the read length) were filtered and converted to the fastq format (all command-line arguments

184 used and custom scripts are available at

185 https://github.com/kmhernan/Publications/tree/master/DesMarais-2016-Brachy-PlantSci). High

186 quality reads were then aligned to the B. distachyon assembly v3.0 (downloaded from

187 Phytozome on 13 August 2015) with SHRiMP v2.2.2 [49] and filtered to remove unmapped and

188 low quality alignments with sambamba v0.5.8 [50]. The remaining alignments were further 189 processed with the Genome Analysis Toolkit (GATK) v3.4-46-gbc02625 [51] following the

190 Broad Institute's “Best Practices” [52] protocol. To recalibrate quality scores, an initial

191 genotyping run was performed with GATK's UnifiedGenotyper to determine high quality SNPs 192 (see [53]).

193 The GATK processed alignments were then used to detect genotypes with freebayes

194 v0.9.21-19-gc003cle [54]. Loci with more than two alleles and genotypes with low quality (GQ

$195<8$ ) were removed using in-house scripts. The remaining genotypes were normalized using vt

196 normalize v0.5 [55]. The normalized, bi-allelic variants were then converted to markers

197 (hereafter referred to as “2b-RAD” data) by comparing the RIL genotypes with Bd21 (parent

198 "A") and Bd3-1 (parent "B"). The 2b-RAD dataset was then cleaned to remove markers that

199 exhibited segregation distortion (A/B frequencies $>60 \%$ ) or that had more than $30 \%$ missing 200 data.

201 After filtering, the 2b-RAD markers were combined with the previously published 202 markers (hereafter referred to as "Cui" data; [40]). First, the genomic coordinates of the Cui data 203 were updated by aligning the flanking sequence of their previously published markers to the $B$. 204 distachyon genome assembly v3.0 using blastn v2.2.31 [56]. The start position of the best hit for 205 each Cui marker was extracted (if available) to determine the approximate location of the 
markers on the assembly v3.0. Then, both Cui and 2b-RAD data were cleaned separately by removing likely genotyping errors (e.g., variant calls that suggest double recombinants in small intervals). The cleaned $2 b-\mathrm{RAD}$ and Cui datasets were then merged and redundant markers were dropped. Linkage analysis was performed on the merged markers using JoinMap 4.1 [57] using the Independence LOD thresholds of 4 to 10 with a step of 1 . Next, marker order and distances were determined by a Maximum Likelihood mapping algorithm. Finally, recombination rates

212 (centiMorgans, cM) were estimated using Kosambi’s mapping function.

\subsection{Phenotyping the Bd3-1 x Bd21 RILs and initial analyses}

215 Ten individuals of each of 151 RILs and both parental lines were planted in a 3:1 mix of ProMix

216 (Premier Tech) and Turface MVP (Turface Athletics) in 3.5" square pots and then cold-stratified 217 for $7 \mathrm{~d}$ at $8^{\circ} \mathrm{C}$. Plants were transferred to the greenhouse facilities at the University of Texas at 218 Austin Brackenridge Field Station in a complete randomized block design. During the initial 219 growth phase, all plants were top-watered with dilute fertilizer, as described above. Throughout 220 the experiment, daytime temperatures ranged from $29-35^{\circ} \mathrm{C}$. We did not artificially supplement 221 the natural mid-summer sunlight in the greenhouse. On day 22 following germination, five 222 plants of each RIL were randomly assigned to each of two treatments: control, and restricted 223 irrigation. Control plants received $100 \mathrm{~mL}$ of unfertilized water every other day, while restricted 224 irrigation plants received $50 \mathrm{~mL}$ of unfertilized water every other day. After $10 \mathrm{~d}$ of treatment, 225 this resulted in soil water contents of 80\% (Control) and 40\% (Dry treatment), determined gravimetrically on the off-watering days. These treatment levels were maintained for $30 \mathrm{~d}$.

We phenotyped and harvested plants on the $52^{\text {nd }}-54^{\text {th }}$ day following germination. 185 of 228 the 1510 plants flowered before this harvest. Flowering individuals were clustered by RIL (e.g. 229 all ten individuals of RIL 52 flowered whereas no individuals of RIL 53 flowered), though at 230 least one individual from 74 of the RILs flowered. All measurements were made on leaves from 231 non-flowering tillers. Leaf chlorophyll content was estimated by taking the mean value from four 232 leaves measured with a SPAD 502DL Plus spectrophotometer (Spectrum Technologies). Above233 ground biomass was excised with a razor blade, dried for $48 \mathrm{hr}$ at $80^{\circ} \mathrm{C}$, and weighed.

234 Subsequently the above-ground tissue from one replicate of each RIL in each environment was 235 ground to a fine powder and analyzed for $\delta^{13} \mathrm{C}$, carbon content, and nitrogen content, as 236 described above. The effect of soil drying on measured traits in the RILs was assessed by 
237 ANOVA including genotype, treatment, their interaction, and greenhouse block as effects, using 238 the JMP software package. We did not fit a GxE term in the ANOVAs for Leaf N, Leaf C, or

$239 \delta^{13} \mathrm{C}$ because only a single individual of each RIL was measured in each environment for those

240 traits. With the exception of leaf $\mathrm{N}$ content, all traits were normally distributed; leaf $\mathrm{N}$ values

241 were log-transformed prior to analysis to meet the assumption of normal distribution. We used

242 this analysis to estimate LSMeans for SPAD and biomass values for each RIL in both irrigation

243 treatments. For leaf $\mathrm{C}$, leaf $\mathrm{N}$, and $\delta^{13} \mathrm{C}$ the value of the single replicate plant in each treatment

244 was used. We also used these LSMeans to estimate the genetic correlation between SPAD and

245 biomass traits and between treatments for SPAD and biomass, and the phenotypic correlations

246 between all traits in JMP.

2.4 QTL mapping in Bd3-1 $x$ Bd21 RILs

249 Following Lowry et al. [58], we used the LSMeans estimates for each measured phenotype to

250 generate two parameters for subsequent QTL scans: the mean of the trait values between the

251 Control and Dry environment measured as (LSMean Dry + LSMean Control)/ 2, and the

252 plasticity of the trait between environments measured as (LSMean Dry - LSMean Control). Our

253 motivation for this mapping strategy was to identify both QTL that contribute to constitutive

254 (main effect QTL) trait variability as well as QTL affecting environmentally-induced trait

255 variability (GxE interaction). We mapped QTL using r/qtl version 1.37 (Broman et al. 2003)

256 with both one- and two-dimensional interval mapping using Haley-Knot regression at $1 \mathrm{cM}$ steps

257 across the genome. Significance thresholds were determined at an experiment-wide Type 1 error

258 rate of $\alpha=0.1$ using 1000 permutations of the marker dataset. We conducted a

259 forward/backward stepwise search for models with a maximum of five QTL that optimized the

260 penalized LOD score criterion using the stepwise procedure. Confidence intervals for each

261 significant QTL identified in the best-fit models were calculated as the 1.5 LOD drop interval.

262 We estimated the additive effect of each QTL as half the difference in phenotypic means

263 for the homozygous genotypes at a locus. Here, $\mathrm{Bd} 21$ was treated as the reference and so the

264 sign of the additive effect indicates the contribution of the Bd3-1 allele to the estimated trait

265 value (e.g. a negative sign indicates that the $\mathrm{Bd} 3-1$ allele decreases the trait mean at that locus).

266 The proportion of total genetic variance explained by each locus, or by interaction between loci

267 (epistasis), was determined using the fitqtl function in r/qtl. 


\section{Results and Discussion}

270

\subsection{Selecting treatment levels and assessing natural diversity of response}

271 We first estimated the progression of plant response to soil drying by measuring leaf relative

272 water content (RWC) along a soil-drying continuum. The results of an ANOVA indicate that our 273 soil-drying resulted in a reduction of leaf RWC as the soil became drier (Figure 1; ANOVA F

274 Harvest Date $\mathrm{x}$ Water Treatment $=25.1, \mathrm{p}<0.0001)$. Visual inspection of Figure 1 suggests that leaves of

275 B. distachyon accession $\mathrm{Bd} 21$ and $\mathrm{Bd} 3-1$ do not show a reduction in RWC until the soil water content (SWC) is reduced to approximately 50\% of field capacity for water. Note that this result

277 does not necessarily indicate that the plants are not responding to soil drying at higher soil water

278 contents; plants have diverse cellular mechanisms to sustain leaf water content in the presence of soil drying, collectively referred to as the dehydration avoidance syndrome [59]. Our results indicate that SWC of approximately $50 \%$ may be an inflection point beyond which these two accessions may no longer maintain constant RWC through such mechanisms. We do not observe genetic variation in reduction of RWC during this progressive soil drying (ANOVA $F$ Genotype $\mathrm{x}$ Harvest Date $\mathrm{x}$ Water Treatment $=0.056, p=0.982$ ).

We next assessed the treatment response of $\mathrm{Bd} 21$ and $\mathrm{Bd} 3-1$ to the strongest drying treatment, contrasting trait values at $85 \%$ soil water content (equivalent to $0.54 \mathrm{~g} \mathrm{H}_{2} \mathrm{O} / \mathrm{g}$ soil) with $40 \%$ soil water content (equivalent to $0.25 \mathrm{~g} \mathrm{H}_{2} \mathrm{O} / \mathrm{g}$ soil). This $\mathrm{SWC}$ resulted in a $28 \%$ reduction in leaf RWC compared to the well-irrigated treatment (Supplemental Figure 1a; ANOVA $F=$ 92.89, $\mathrm{p}<0.0001)$. Compared to well-watered control plants, dry treatment plants had 17\% lower total dry biomass (Supplemental Figure 1b; ANOVA $F=5.79, p=0.033$ ) with a higher root/shootmass ratio (Supplemental Figure 1c; ANOVA $F=17.02, p=0.014$ ). Soil drying also

293 Figure 1e; ANOVA $F=21.63, p=0.0007$ ), and lower leaf nitrogen content (Supplemental

294 Figure 1f; ANOVA $F=33.34, p<0.0001)$. The increase in WUE under soil drying is 295 comparable in magnitude to those identified in past studies using both experimentally dried pot296 grown B. distachyon plants (e.g. [22]) as well as under drought conditions of wheat varieties 297 grown in the field (e.g. [60]). We observed some constitutive genetic diversity in these traits. 298 On average, Bd3-1 plants had 44.9\% greater biomass (Supplemental Figure 1b; ANOVA 
$\left.299 \quad F_{\text {Genotype }}=14.98, p=0.0022\right)$, with higher root/shoot mass ratio (Supplemental Figure 1c;

300 ANOVA $F=11.55, p=0.0053$ ) and lower WUE (Supplemental Figure 1d; ANOVA $F=8.50, p$

$301=0.0129)$ regardless of treatment. No measured traits showed significant genetic variation in

302 response to soil drying $(\mathrm{GxE})$, although leaf $\mathrm{N}$ showed a trend towards greater reduction under

303 soil drying in Bd3-1 as compared to Bd21 (Supplemental Figure 1f; ANOVA $F_{\text {Genotype } x \text { Water }}=$

$3044.59, p=0.055)$.

3.2 New markers and revised linkage map for the Bd3-1 $x$ Bd21 RIL population

307 Cui et al. [40] previously reported a genetic map for the $\mathrm{Bd} 3-1 \times \mathrm{Bd} 21$ mapping population and

308 used it to map a gene associated with resistance to Barley Stripe Mosaic Virus. We updated this

309 linkage map in three ways. First, we identify the approximate physical position of the Cui

310 markers on the most recent release of the $\mathrm{Bd} 21$ reference genome. Second, we removed

311 potentially mis-called markers in the Cui dataset by identifying marker assignments that led to

312 the inference of double recombination events over very short map distances. Finally, we identify

313150 new genetic markers using reduced-representation genome resequencing of 151 RILs from

314 the population. We combined the "cleaned" Cui markers with our new resequenced markers and

315 present a newly estimated linkage map comprised of 490 markers across $1017 \mathrm{cM}$, with average

316 intermarker distance $\sim 2 \mathrm{cM}$ (Figure 2 and Supplemental Table 1). This total map length is

317 shorter than the map previously reported by Cui et al., possibly owing to mis-called markers in

318 the earlier dataset resulting in double recombinants over very short distances, but remains

319 relatively long and highlights the generally high recombination rate in this mapping population

320 [37]. The median inter-marker distance on the physical genome is 272 kilobase pairs. Notable

321 gaps in marker coverage remain between 90.8 and 93.1cM ( 6.4 M.b.p) and 133.1 and 147.0

322 ( 3.2 M.b.p) on chromosome 2 and between 35.6 and 44.6 ( 3.1 M.b.p) on chromosome 5.

323 These gaps in marker coverage may simply reflect an absence of nucleotide variants between the 324 Bd21 and Bd3-1 genomes.

325 This revised and extended linkage map provides several benefits over the existing linkage 326 map available for the $\mathrm{Bd} 3-1 \times \mathrm{Bd} 21$ mapping population. First, the additional markers provide

327 higher resolution for linkage mapping and will facilitate fine-mapping efforts and construction of 328 near isogenic lines. Second, there have been considerable changes in the reference genome 329 sequence following its initial release [36]. By updating the positions of the earlier Cui markers 
330 the new map should allow researchers to more readily identify candidate genes associated with

331 genetic loci and exploit the genomic synteny between grass species to identify orthologous loci

332 in temperate cereals. Finally, we have removed possible genotyping errors from the earlier

333 dataset which may have led to reduced statistical power to detect trait-marker associations.

\subsection{Quantitative genetics of measured traits in the Bd3-1 $x$ Bd21 RILs}

336 We grew replicates of each of 151 RILs in a controlled-environment greenhouse experiment and

337 exposed plants to either well-watered (control) or restricted-irrigation (dry) treatments.

338 Comparison of the trait means for each parent against the frequencies of line means among RILs 339 reveals that all of our measured traits show considerable transgressive segregation (Figure 3 and

340 Supporting online Figure 2). This pattern has been observed previously in other plant species for 341 WUE [21, 23, 24, 26] and plant biomass [24], among many other traits [61], and indicates that 342 phenotypic variation in the traits is likely due to variation at multiple genetic loci, possibly with 343 parental allelic affects in different directions at each locus which have been recombined among 344 RILs. Transgressive segregation may also indicate epistatic interactions among loci controlling 345 these traits. The range of $\delta^{13} \mathrm{C}$ values observed among RILs $(-32.65--30.17 \%$ ) is comparable 346 to the difference of 2-3\%o observed among varieties of wheat, barley, rice, and several forage and 347 turf grasses (reviewed by [13]).

348 Broad-sense heritabilities of measured traits, measured as the proportion of total

349 phenotypic variance explained by variance among RILs, were appreciable. Heritability for total 350 above ground dry biomass was 0.63 in the well-watered environment and slightly lower, 0.55 , in 351 the water-restricted environment. Chlorophyll content, estimated using a SPAD

352 spectrophotometer, was lower than biomass heritabilities: 0.36 in the well-watered environment 353 and 0.43 in the water-restricted environment. Because we only assayed $\delta^{13} \mathrm{C}$, leaf $\mathrm{C}$, and leaf $\mathrm{N}$ 354 for a single individual of each RIL in each treatment, our sampling scheme precluded us from 355 estimating heritabilities for these traits; we present a QTL-based approximation of heritable 356 variance for these traits below. In past experiments in wheat, estimated heritabilities for carbon 357 isotope discrimination have generally been quite high, suggesting that GxE may be moderate for 358 this trait, thus providing high power to detect QTL explaining genetic differences in WUE [32, $35962]$. 
We observed a strong positive genetic correlation between above ground biomass and leaf chlorophyll content $($ rho $=0.58)$, which was considerably stronger than the phenotypic correlation between these traits $($ rho $=0.26)$. Several of the differences in trait means

363 (plasticities) between environments also showed significant, positive phenotypic correlations

364 (Supp Table 2). Notably, plasticity in leaf $\mathrm{C}$, leaf $\mathrm{N}$, and $\delta^{13} \mathrm{C}$ are all positively correlated, as is

365 plasticity in leaf $\mathrm{C}$ and plasticity in biomass. Collectively, these results suggest that these

366 components of primary metabolism share a genetic basis in both their constitutive expression and

367 their response to soil drying.

\subsection{Effect of drying treatment on traits in the RIL experiment}

370 In our RIL greenhouse experiment, soil drying lead to a significant $23 \%$ decrease in plant

371 biomass (Supplemental Figure 3a; ANOVA $F=265, p<0.0001$ ), a 21\% increase in SPAD

372 measurement (Supplemental Figure 3b; ANOVA $F=285.7, p<0.0001$ ), a $3.0 \%$ increase in leaf

373 carbon content (Supplemental Figure 3c; ANOVA $F=38.1, \mathrm{p}<0.0001$ ), and a $24.7 \%$ increase

374 in leaf nitrogen content (Supplemental Figure 3d; ANOVA $F=36.5, p<0.0001$; both leaf C and

375 leaf $\mathrm{N}$ expressed on a dry leaf weight basis). $\delta^{13} \mathrm{C}$ also increased by $0.42 \%$ in the dry

376 environment in our greenhouse experiment (Supplemental Figure 3e; ANOVA $F=50.0, p<$

377 0.0001). Representative plants from each treatment are presented in Supplemental Figure 4.

378 The observation that leaf $\mathrm{N}$ is elevated under soil drying in the greenhouse RIL

379 experiment conflicts with the observed decrease in leaf $\mathrm{N}$ under drying in the growth chamber

380 experiment, described above. Regardless of experimental treatment, leaf $\mathrm{N}$ concentrations were

381 substantially lower in the greenhouse-grown plants as compared to chamber grown plants (cf.

382 Supplemental Figure 1f and Supplemental Figure 3d). There were several important differences

383 between the greenhouse and chamber experiments, notably that the greenhouse plants received

384 considerably higher light levels of different quality (natural sunlight vs. artificial broad-spectrum

385 fluorescence) that the greenhouse plants were older at harvest (54 d post germination compared

386 to $30 \mathrm{~d}$ in the chamber experiment). The elevated leaf $\mathrm{N}$ under water-restriction, observed in the

387 greenhouse, is consistent with results from our earlier work in Arabidopsis thaliana in which the

388 increase in leaf $\mathrm{N}$ was correlated with a transcriptional signature of increased investment in

389 photosynthetic machinery [4]. We interpreted the increase in leaf $\mathrm{N}$ as signifying changes in 
390 photosynthetic capacity, perhaps related to increased carbon acquisition directed towards root 391 growth as a dehydration avoidance response.

\subsection{Identifying QTL associated with plant-water relations}

394 Our analysis of the greenhouse-grown Bd3-1 x Bd21 RILs provides two key results which improve our understanding of the genetic basis of plant-water relations in B. distachyon and grasses, more generally. First, we identify six QTL explaining constitutive trait variation between $\mathrm{Bd} 21$ and $\mathrm{Bd} 3-1$ (Table 1). In this analysis of constitutive-effect QTL, we used the mean trait value between the two sampled environments in model fitting. Four of these constitutive QTL are associated with WUE, measured here as carbon isotope discrimination $\left(\delta^{13} \mathrm{C}\right)$; we assign the prefix "delta" for these $\delta^{13} \mathrm{C}$ QTL (Figure 4). Collectively, the four $\delta^{13} \mathrm{C}$ QTL explain $37.5 \%$ of the total genetic variance in $\delta^{13} \mathrm{C}$ in the mapping population. In the 402 absence of a direct estimate for heritability of WUE, this percent of variance explained by the 403 four QTL gives an approximation of the proportion of phenotypic variance that can be explained by the detected genetic factors. The additive effect of these $\delta^{13} \mathrm{C}$ QTL are generally larger than observed previously in field-grown wheat mapping populations [24], though comparable in magnitude to the effects of loci identified in a greenhouse-grown rice population [26]. As predicted by the transgressive segregation observed for $\delta^{13} \mathrm{C}$, the additive effects of parental alleles differ in magnitude and direction among loci, with Bd3-1 alleles at delta-2.1 and delta-2.2 reducing $\delta^{13} \mathrm{C}$ values and those at delta-3.1 and delta-5.1 increasing $\delta^{13} \mathrm{C}$ values. We also find

411 QTL model for this interaction $\mathrm{LOD}=5.325, p<0.001)$. The epistatic interaction between these 412 two QTL explains 11.03\% of the variance in WUE in the Bd3-1 x Bd21 cross.

Notably, we do not observe any QTL which describe phenotypic difference in $\delta^{13} \mathrm{C}$

414 between the control and restricted-irrigation environments, indicating that there are no QTL for

415 plasticity in $\delta^{13} \mathrm{C}$. This suggests that the genetic architecture controlling WUE in B. distachyon 416 may be relatively canalized. Rebetzke et al. [24] previously reported similarly strong

417 constitutive effects of QTL controlling $\delta^{13} \mathrm{C}$ in several varieties of wheat grown in multiple 418 experimental field plots of wheat, which contrasted with the strong GxE observed for yield and 419 biomass in that experiment. Note that neither our results, nor those reported previously for wheat, reject the hypothesis that WUE is a plastic trait: numerous studies have shown that soil 
421 drying generally leads to increased WUE [22, 60, 63, 64] and we also observed this pattern in 422 both our chamber and greenhouse experiments. Indeed, GxE for WUE has been detected in 423 several grass species [65, 66].

424 The absence of plasticity QTL for $\delta^{13} \mathrm{C}$ indicates that the largest-effect QTL in the Bd3-1

$425 \times \mathrm{Bd} 21$ cross are generally insensitive to environmental change and suggests that what GxE 426 exists for WUE may be controlled by loci of generally smaller effect. WUE plasticity loci may 427 also have complex patterns of inheritance - such as dominance, epistastis, tightly linked loci of 428 opposing allelic effect, etc. -- that make detecting their genetic basis experimentally challenging. 429 An important caveat for our study is that we have sampled limited genetic diversity - just two 430 accessions from modern-day Iraq - and so absence of GxE for WUE or other traits may not 431 reflect patterns observed in larger panels of natural accessions; a recent study using a larger 432 panel of B. distachyon natural accessions revealed extensive GxE for WUE [22].

433 We also identify two QTL associated with genetic variability in total above-ground dry

434 biomass. Again, here we fit the mean above ground biomass between the two sampled 435 environments. These QTL are of relatively small effect, with the Bd21 allele at the biomass-2 436 locus leading to larger plants at both loci. Of note, $\mathrm{Bd} 3-1$ is a larger plant than $\mathrm{Bd} 21$ under a 437 range of environmental conditions $[45,46]$ so it is perhaps surprising that we did not detect more 438 QTL describing this phenotypic difference. A possible explanation for this discrepancy is that 439 biomass may be controlled by many loci of small effect which were not detected in our mapping 440 efforts. The observation that our best-fit qtl model explains a small fraction of observed 441 heritable genetic variation support this hypothesis: the two detected QTL explain just 16\% of 442 genetic variance whereas our estimate of heritability for above ground biomass was over 0.5 in 443 both sampled environments.

444 The second observation from our mapping analysis is the presence of an 445 environmentally-dependent QTL (indicating GxE; mapped on the difference between dry and 446 wet environments) for leaf carbon content on chromosome 1. This environmental effect is due to 447 a genetic difference in leaf $\mathrm{C}$ content in the wet environment that is absent in the dry 448 environment (Figure 6; results of the full stepwise QTL model for this interaction LOD $=3.46, p$ $449<0.001$ ), a genetic architecture called conditional neutrality [67]. Conditionally-neutral genetic 450 loci are of potential interest for plant breeding because the beneficial effects of an allele in one 
451 environment - here, relatively greater leaf $\mathrm{C}$ conferred by the $\mathrm{Bd} 3-1$ allele when water is

452 plentiful - is not associated with a difference in trait values in a second environment.

453 We do not detect QTL for leaf $\mathrm{N}$ or SPAD at an experiment-wide $\alpha=0.1$. As noted

454 above, heritabilities for SPAD were relatively lower than for above ground biomass, indicating a 455 greater contribution of environmental factors in explaining experimental variance. These low

456 heritabilities may have prevented us from detecting QTL for this trait.

457 One striking result from our QTL analysis is that we observe significant phenotypic

458 correlations among several of our traits (Supplemental Table 2), though none of the QTL

459 detected at $\alpha=0.1$ overlap with another QTL (e.g. the 1.5 LOD intervals around QTL peaks do

460 not overlap). One explanation for this observation is that the traits studied here are controlled by

461 additional loci of small effect, possibly in an environmentally-dependent manner, leaving us with

462 little statistical power to detect QTL and thereby little power to detect co-localization of QTL for

463 different traits [68, 69].

\subsection{Concluding remarks}

466 Plant responses to soil drying are complex, involving changes in primary and secondary

467 metabolism, biomass partitioning, cell wall composition, transpiration, and hydraulic

468 adjustments, to name but a few. These responses vary substantially within and between species,

469 and according to the duration, developmental timing, and severity of stress. This experimental

470 and genetic variation has complicated efforts to develop a clear picture of what responses are

471 truly adaptive - i.e. favored by natural selection to increase fitness under stressful conditions. In

472 particular, interpreting the effects of water limitation on primary metabolic activity and

473 photosynthate partitioning is an enduring challenge [70]. Several recent studies in A. thaliana

474 shed light on this key issue, revealing that moderate soil drying - similar to the stress imposed

475 here - increases plant carbon status as revealed by transcriptional signature of elevated carbon

476 assimilation and high leaf $\mathrm{C}$ and leaf $\mathrm{N}$ content $[4,71,72]$. Recent work in B. distachyon $(\mathrm{Bd} 21$

477 accession) likewise found no transcriptional signature of carbon limitation and, in fact, observed

478 that leaf cell division continued unabated during soil drying though cell expansion was

479 significantly curtailed [73]. This "wait and see" growth response to stressful conditions may be

480 favored in environments with unpredictable rainfall during the growing season. 
Our greenhouse results are consistent with these earlier studies. First, we observe elevated leaf $\mathrm{C}, \mathrm{N}$, and SPAD readings under moderate soil drying, all consistent with the

483 hypothesis that these plants remain photosynthetically active. While we did not measure root-

484 shoot biomass ratios in the greenhouse experiment, our chamber experiment revealed increased

485 relative investment in root tissue, which is a frequently observed response to soil drying that would require sustained carbon assimilation in this short-lived annual species.

The QTL which detected here represent an important first step in identifying the molecular basis of WUE, leaf carbon content, and plant biomass in this important model grass species. Importantly, unlike genetic loci identified via gene artificial mutagenesis screens, the variants discovered by QTL mapping are viable in the field (by virtue of existing in wild-

491 collected accessions) and therefore may reveal orthologous loci which are amenable to manipulative breeding in crop species. Our revised genetic map for the Bd3-1 by B21 mapping

493 population may prove useful for this translational approach. The conditionally-neutral allele

494 which we identified for leaf carbon content may be of particular interest, in this regard, as conditionally neutral alleles can circumvent the problems associated with yield-drag when 496 breeding for yield in specific environments [67].

\section{Acknowledgements}

499 Colin Purmal, Kathleen Burns, Emeline Sukamtoh, Omar Gonzales, and Erin Atkinson assisted 500 with RIL phenotyping. Tierney Logan extracted DNA and prepared the SOLiD libraries for 501 sequencing. Comments from E. Blumwald and two anonymous reviewers greatly improved the 502 manuscript. This work was supported by a USDA NIFA award (2011-67012-30663) to D.L.D., 503 an NSF Post-doctoral Research Fellowship (DBI-1103668) to K.M.H, USDA CRIS Project 504 Award (5062-21000-030-00D) to D.F.G., and an NSF Plant Genome Research Program award 505 (IOS-0922457) to T.E.J..

\section{References}

[1] H.J. Bohnert, D.E. Nelson, R.G. Jensen, Adaptations to environmental stresses, Plant Cell, 7 (1995) 1099-1111.

512 [3] R.H. Whittaker, Communities and Ecosystems, 2nd ed., Macmillan, New York, 1975. 
[4] D.L. Des Marais, J.K. McKay, J.H. Richards, S. Sen, T. Wayne, T.E. Juenger, Physiological genomics of response to soil drying in diverse Arabidopsis accessions, Plant Cell, 24 (2012) 893-914.

[5] L.A. Donovan, S.A. Dudley, D.M. Rosenthal, F. Ludwig, Phenotypic selection on leaf water use efficiency and related ecophysiological traits for natural populations of desert sunflower, Oecologia, 152 (2007) 13-25.

[6] H.M. Easlon, K.S. Nemali, J.H. Richards, D.T. Hanson, T.E. Juenger, J.K. McKay, The physiological basis for genetic variation in water use efficiency and carbon isotope composition in Arabidopsis thaliana, Photosynthesis research, 119 (2014) 119-129.

[7] M.A. Geber, T. Dawson, Genetic variation in stomatal and biochemical limitations to photosynthesis in the annual plant, Polygonum arenastrum, Oecologia, 109 (1997) 535-546.

[8] M.S. Heschel, K. Donohue, N. Hausmann, J. Schmitt, Population differentiation and natural selection for water-use efficiency in Impatiens capensis (Balsaminaceae), International Journal of Plant Science, 163 (2002) 907-912.

[9] K.T. Hubick, G.D. Farquhar, Carbon isotope discrimination and the ratio of carbon gained to water lost in barley cultivars, Plant Cell and Environment, 12 (1989) 795-804.

[10] J.E. Quisenberry, B.L. McMichael, Genetic variation among cotton germplasm for wateruse efficiency, Environmental and Experimental Botany, 31 (1991) 433-460.

[11] R. Van den Boogard, D. Alewijnse, E.J. Veneklaas, H. Lambers, Growth and water-use efficiency of 10 Triticum aestivum cultivars at different water availability in relation to allocation of biomass, Plant Cell and Environment, 20 (1997) 200-210.

[12] H. Lambers, F.S. Chapin III, T.L. Pons, Plant Physiological Ecology, 2nd ed., Springer, New York, NY, 2008.

[13] A.G. Condon, G.D. Farquhar, G.J. Rebetzke, R.A. Richards, The application of carbon isotope discrimination in cereal improvement for water-limited environments, in: J.M. Ribaut (Ed.) Drought Adaptation in Cereals, Haworth Press, Inc, New York, NY, 2006, pp. 171-219.

[14] G.D. Farquhar, R.A. Richards, Isotopic composition of plant carbon correlates with wateruse efficiency of wheat genotypes, Australian Journal of Plant Physiology, 11 (1984) 539552.

[15] G.D. Farquhar, J.R. Ehleringer, K.T. Hubick, Carbon isotope discrimination and photosynthesis, Annual Review of Plant Physiology and Plant Molecular Biology, 40 (1989) 503-538.

[16] J.P. Comstock, S.R. McCouch, B.C. Martin, C.G. Tauer, T.J. Vision, Y. Xu, R.C. Pausch, The effects of resource availability and environmental conditions on genetic rankings for carbon isotope discrimination during growth in tomato and rice, Functional Plant Biology, 32 (2005) 1089-1105.

[17] J.K. McKay, J.H. Richards, T. Mitchell-Olds, Genetics of drought adaptation in Arabidopsis thaliana: I. Pleiotropy contributes to genetic correlations among ecological traits, Molecular Ecology, 12 (2003) 1137-1151.

[18] F. Vasseur, T. Bontpart, M. Dauzat, C. Granier, D. Vile, Multivariate genetic analysis of plant responses to water deficit and high temperature revealed contrasting adaptive strategies, J Exp Bot, 65 (2014) 6457-6469.

[19] A.P. Dhanapal, R.J. D., S.K. Singh, V. Hoyos-Villegas, J.R. Smith, L.C. Purcell, C. Andy King, P.B. Cregan, Q. Song, F.B. Fritschi, Genome-wide association study (GWAS) of carbon isotope ratio $(\delta 13 \mathrm{C})$ in diverse soybean [Glycine max (L.) Merr.] genotypes, Theor Appl Genet, 128 (2015) 73-91. 
[20] N.J. Hausmann, T.E. Juenger, S. Sen, K.A. Stowe, T.E. Dawson, E.L. Simms, Quantitative Trait Loci Affecting delta-13C and Response to Differential Water Availability in Arabidopsis thaliana, Evolution, 59 (2005) 81-96.

[21] T.E. Juenger, J. McKay, N. Hausmann, J. Keurentjes, S. Sen, K. Stowe, T. Dawson, E. Simms, J. Richards, Identification and Characterization of QTL Underlying Whole-Plant Physiology in Arabidopsis thaliana: delta C 13, Stomatal Conductance and Transpiration Efficiency, Plant, Cell and Environment, 28 (2005) 697-708.

[22] A.J. Manzaneda, P.J. Rey, J.T. Anderson, E. Raskin, C. Weiss-Lehman, T. Mitchell-Olds, Natural variation, differentiation and genetic tradeoffs of ecophysiological traits in response to water limitation in Brachypodium distachyon and its descendent allotetraploid B. hybridum (Poaceae), Evolution, 69 (2015) 2689-2704.

[23] J.K. McKay, J.H. Richards, K.S. Nemali, S. Sen, T. Mitchell-Olds, S. Boles, E.A. Stahl, T. Wayne, T.E. Juenger, Genetics of drought adaptation in Arabidopsis thaliana II. QTL analysis of a new mapping population, KAS-1 x TSU-1, Evolution, 62 (2008) 3014-3026.

[24] G.J. Rebetzke, A.G. Condon, G.D. Farquhar, R. Appels, R.A. Richards, Quantitative trait loci for carbon isotope discrimination are repeatable across environments and wheat mapping populations, Theoretical and Applied Genetics, 118 (2008) 123-137.

[25] X. Xu, B. Martin, J.P. Comstock, T.J. Vision, C.G. Tauer, B. Zhao, R.C. Pausch, S. Knapp, Fine mapping a QTL for carbon isotope composition in tomato, Theor Appl Genet, 117 (2008) 221-233.

[26] Y. Xu, D. This, R.C. Pausch, W.M. Vonhof, J.R. Coburn, J.P. Comstock, S.R. McCouch, Leaf-level water use efficiency determined by carbon isotope discrimination in rice seedlings: genetic variation associated with population structure and QTL mapping, Theor Appl Genet, 118 (2009) 1065-1081.

[27] J.T. Lovell, T.E. Juenger, S.D. Michaels, J.R. Lasky, A. Platt, J.H. Richards, X. Yu, H.M. Easlon, S. Sen, J.K. McKay, Pleiotropy of FRIGIDA enhances the potential for multivariate adaptation, Proc Biol Sci, 280 (2013) 20131043.

[28] J. Masle, S.R. Gilmore, G.D. Farquhar, The ERECTA Gene Regulates Plant Transpiration Efficiency in Arabidopsis, Nature, 436 (2005) 866-870.

[29] D.L. Des Marais, L.C. Auchincloss, E. Sukamtoh, J.K. McKay, T. Logan, J.H. Richards, T.E. Juenger, Variation in MPK12 affects water use efficiency in Arabidopsis and reveals a pleiotropic link between guard cell size and ABA response, Proceedings of the National Academy of Sciences, 111 (2014) 2836-2841.

[30] P. Monneveux, R. Jing, S.C. Misra, Phenotyping for drought adaptation in wheat using physiological traits, Frontiers in physiology, 3 (2012) 429.

[31] R. Tuberosa, Mapping QTLs Regulating Morpho-physiological Traits and Yield: Case Studies, Shortcomings and Perspectives in Drought-stressed Maize, Annals of Botany, 89 (2002) 941-963.

[32] G.J. Rebetzke, A.G. Condon, R.A. Richards, G.D. Farquhar, Selection for reduced carbon isotope discrimination increases aerial biomass and grain yield of rainfed bread wheat, Crop Science, 42 (2002) 739-745.

[33] B.E. Campitelli, D.L. Des Marais, T.E. Juenger, Ecological interactions and the fitness effect of water-use efficiency: Competition and drought alter the impact of natural MPK12 alleles in Arabidopsis, Ecol Lett, (2016). 
603
[34] P. Catalan, J. Muller, R. Hasterok, G. Jenkins, L.A. Mur, T. Langdon, A. Betekhtin, D. Siwinska, M. Pimentel, D. Lopez-Alvarez, Evolution and taxonomic split of the model grass Brachypodium distachyon, Annals of Botany, 109 (2012) 385-405.

[35] J. Vogel, Genetics and Genomics of Brachypodium, in: R. Jorgensen (Ed.) Plant Genetics and Genomics: Crop Models, Springer, 2016.

[36] The International Brachypodium Initiative, Genome sequencing and analysis of the model grass Brachypodium distachyon, Nature, 463 (2010) 763-768.

[37] D.F. Garvin, Brachypodium distachyon genetic resources, in: J. Vogel (Ed.) Genetics and Genomics of Brachypodium, Springer, 2016.

[38] S. Gordon, H. Priest, D.L. Des Marais, W. Schackwitz, M. Figueroa, J. Martin, J. Bragg, L. Tyler, C.-R. Lee, D. Bryant, W. Wang, J. Messing, A. Manzaneda, K. Barry, D. Garvin, H. Budak, M. Tuna, T. Mitchell-Olds, W. Pfender, T. Juenger, T.C. Mockler, J. Vogel, Genome Diversity in Brachypodium distachyon: Deep Sequencing of Highly Diverse Inbred Lines, The Plant Journal, 79 (2014) 361-374.

[39] C.J. Schwartz, M.R. Doyle, A.J. Manzaneda, P.J. Rey, T. Mitchell-Olds, R.M. Amasino, Natural variation of flowering time and vernalization responsiveness in Brachypodium distachyon, Bioenergy research, 3 (2010) 38-46.

[40] Y. Cui, M.Y. Lee, N. Huo, J. Bragg, L. Yan, C. Yuan, C. Li, S.J. Holditch, J. Xie, M.-C. Luo, D. Li, J. Yu, J. Martin, W. Schackwitz, Y.Q. Gu, J.P. Vogel, A.O. Jackson, Z. Liu, D.F. Garvin, Fine Mapping of the Bsrl Barley Stripe Mosaic Virus Resistance Gene in the Model Grass Brachypodium distachyon, PLoS One, 7 (2012) e38333.

[41] V. Chochois, J. Vogel, G.J. Rebetzke, M. Watt, Variation in adult plant phenotypes and partitioning among seed and stem-borne roots across Brachypodium distachyon accessions to exploit in breeding cereals for well-watered and drought environments, Plant Physiology, 168 (2015) 953-967.

[42] K. Colton-Gagnon, M.A. Ali-Benali, B.F. Mayer, R. Dionne, A. Bertrand, S. Do Carmo, J.B. Charron, Comparative analysis of the cold acclimation and freezing tolerance capacities of seven diploid Brachypodium distachyon accessions, Ann Bot, 113 (2014) 681-693.

[43] E. Filiz, B.S. Ozdemir, F. Budak, J.P. Vogel, M. Tuna, H. Budak, Molecular, morphological and cytological analysis of diverse Brachypodium distachyon inbred lines, Genome, 52 (2009) 876-890.

[44] P.A. Ingram, J. Zhu, A. Shariff, I.W. Davis, P.N. Benfey, T. Elich, High-throughput imaging and analysis of root system architecture in Brachypodium distachyon under differential nutrient availability, Philosophical transactions of the Royal Society of London. Series B, Biological sciences, 367 (2012) 1559-1569.

[45] N. Luo, J. Liu, X. Yu, Y. Jiang, Natural variation of drought response in Brachypodium distachyon, Physiologia Plantarum, 141 (2011) 19-29.

[46] L. Tyler, J.U. Fangel, A.D. Fagerström, M.A. Steinwand, T.K. Raab, W.G.T. Willats, J.P. Vogel, Selection and phenotypic characterization of a core collection of Brachypodium distachyon inbred lines, BMC Plant Biol, 14 (2014) 25.

[47] A.J. Kelly, J.H. Willis, Polymorphic microsatellite loci in Mimulus guttatus and related species, Molecular Ecology Notes, 7 (1998) 769-774.

[48] S. Wang, E. Meyer, J.K. McKay, M.V. Matz, 2b-RAD: a simple and flexible method for genome-wide genotyping, Nat Methods, 9 (2012) 808-810.

[49] M. David, M. Dzamba, D. Lister, L. Ilie, M. Brudno, SHRiMP2: sensitive yet practical short read mapping, Bioinformatics, 27 (2011) 1011-1012. 
[50] A. Tarasov, A.J. Vilella, E. Cuppen, I.J. Nijman, P. Prins, Sambamba: fast processing of NGS alignment formats, Bioinformatics, (2015) btv098.

[51] A. McKenna, M. Hanna, E. Banks, A. Sivachenko, K. Cibulskis, A. Kernytsky, K. Garimella, D. Altshuler, S. Gabriel, M. Daly, M.A. DePristo, The Genome Analysis Toolkit: a MapReduce framework for analyzing next-generation DNA sequencing data, Genome Res, 20 (2010) 1297-1303.

[52] G.A.V. de Auwera, M.O. Carneiro, C. Hartl, R. Poplin, G. del Angel, A. Levy- Moonshine, T. Jordan, K. Shakir, D. Roazen, J. Thibault, E. Banks, K.V. Garimella, D. Altshuler, S. Gabriel, M.A. DePristo, From fastq data to high-confidence variant calls: The genome analysis toolkit best practices pipeline, Current Protocols in Bioinformatics, 11 (2013) 11.10.11-11.10.33.

[53] D.B. Lowry, K. Hernandez, S.H. Taylor, E. Meyer, T.L. Logan, K.W. Barry, J.A. Chapman, D.S. Rokhsar, J. Schmutz, T.E. Juenger, The genetics of divergence and reproductive isolation between ecotypes of Panicum hallii, New Phytol, 205 (2015) 402-414.

[54] E. Garrison, G. Marth, Haplotype-based variant detection from short-read sequencing, arXiv preprint (2012) 1207.3907.

[55] A. Tan, G.R. Abecasis, H.M. Kang, Unified representation of genetic variants, Bioinformatics, 31 (2015) 2202-2204.

[56] C. Camacho, G. Coulouris, V. Avagyan, N. Ma, J. Papadopoulos, K. Bealer, T.L. Madden, BLAST+: architecture and applications, BMC Bioinformatics, 10 (2009) 421.

[57] J.W. Van Ooijen, JoinMap 4, Software for the calculation of genetic linkage maps in experimental populations, in, Kyazma B.V., Wageningen, Netherlands, 2006.

[58] D.B. Lowry, T.L. Logan, L. Santuari, C.S. Hardtke, J.H. Richards, L.J. DeRose-Wilson, J.K. McKay, S. Sen, T.E. Juenger, Expression quantitative trait locus mapping across water availability environments reveals contrasting associations with genomic features in Arabidopsis, Plant Cell, 25 (2013) 3266-3279.

[59] M.M. Ludlow, Strategies of response to water stress, in: K.H. Kreeb, H. Richter, T.M. Hinckley (Eds.) Structural and Functional Responses to Environmental Stresses, SPB Academic, The Hague, 1989, pp. 269-281.

[60] O. Merah, E. Deleens, P. Monneveux, Grain yield, carbon isotope discrimination, mineral and silicon content in durum wheat under different precipitation regimes, Crop Science, 107 (1999) 387-394.

[61] L.H. Rieseberg, A. Widmer, A.M. Arntz, J.M. Burke, The genetic architecture necessary for transgressive segregation is common in both natural and domesticated populations, Philosophical transactions of the Royal Society of London. Series B, Biological sciences, 358 (2003) 1141-1147.

[62] G.J. Rebetzke, R.A. Richards, A.G. Condon, G.D. Farquhar, Inheritance of carbon isotope discrimination in bread wheat, Euphytica, 150 (2006) 97-106.

[63] A.G. Condon, R.A. Richards, G.D. Farquhar, The effect of variation in soil water availability, vapour pressure deficit, and nitrogen nutrition on carbon isotope discrimination in wheat, Australian Journal of Agricultural Research, 43 (1992).

[64] D. Rengel, S. Arribat, P. Maury, M.L. Martin-Magniette, T. Hourlier, M. Laporte, D. Vares, S. Carrere, P. Grieu, S. Balzergue, J. Gouzy, P. Vincourt, N.B. Langlade, A gene-phenotype network based on genetic variability for drought responses reveals key physiological processes in controlled and natural environments, PLoS One, 7 (2012) e45249. 
694

[65] Z. Peleg, T. Fahima, S. Abbo, T. Krugman, E. Nevo, D. Yakir, Y. Saranga, Genetic diversity for drought resistance in wild emmer wheat and its ecogeographical associations, Plant Cell and Environment, 2 (2005) 176-191.

[66] D. Robinson, L.L. Handley, C.M. Scrimgeour, D.C. Gordon, B.P. Forster, R.P. Ellis, Using stable isotope natural abundances (delta-15N and delta-13C) to integrate the stress responses of wild barley (Hordeum spontaneum C. Koch) genotypes, Journal of Experimental Botany, 51 (2000) 41-50.

[67] D.L. Des Marais, K.H. Hernandez, T.E. Juenger, Genotype-by-environment interaction and plasticity: exploring genomic responses of plants to the abiotic environment, Annual Review of Ecology, Evolution and Systematics, 44 (2013) 5-29.

[68] G. Gibson, Rare and common variants: twenty arguments, Nature reviews. Genetics, 13 (2012) 135-145.

[69] M.V. Rockman, The QTN program and the alleles that matter for evolution: all that's gold does not glitter, Evolution, 66 (2012) 1-17.

[70] C. Pinheiro, M.M. Chaves, Photosynthesis and drought: Can we make metabolic connections from available data?, Journal of Experimental Botany, 62 (2011) 869-882.

[71] I. Hummel, F. Pantin, R. Sulpice, M. Piques, G. Rolland, M. Dauzat, A. Christophe, M. Pervent, M. Bouteillé, M. Stitt, Y. Gibon, B. Muller, Arabidopsis Plants Acclimate to Water Deficit at Low Cost through Changes of Carbon Usage: An Integrated Perspective Using Growth, Metabolite, Enzyme, and Gene Expression Analysis, Plant Physiology, 154 (2010) 357-372.

[72] A. Skirycz, S. De Bodt, T. Obata, I. De Clercq, H. Claeys, R. De Rycke, M. Andriankaja, O. Van Aken, F. Van Breusegem, A.R. Fernie, D. Inze, Developmental stage specificity and the role of mitochondrial metabolism in the response of Arabidopsis leaves to prolonged mild osmotic stress, Plant Physiol, 152 (2010) 226-244.

[73] W. Verelst, E. Bertolini, S. De Bodt, K. Vandepoele, M. Demeulenaere, M.E. Pe, D. Inze, Molecular and physiological analysis of growth-limiting drought stress in Brachypodium distachyon leaves, Mol Plant, 6 (2013) 311-322.

\section{Figure Legends}

Figure 1 - Leaf relative water content from the growth chamber dry-down. Bd3-1 individuals are shown as black boxes. Bd21 individuals are shown as white boxes. Boxes are "jittered" to ease viewing. Vertical bars indicate one standard error of the mean. $\mathrm{N}=4$ for each box.

Figure 2 - Graphical representation of the newly estimated linkage map for the $\mathrm{Bd} 3-1 \mathrm{x} \mathrm{Bd} 21$ RIL mapping population. Numbers along the left side of linkage groups indicate marker position in cM. Labels along the right side of linkage groups indicate marker names; those in bold are new markers generated in the present study. For new markers, names denote chromosome number before colon and physical position in the B. distachyon v3.0 genome is indicated following the colon. 
733 Figure 3 - Frequency distributions of $\delta^{13} \mathrm{C}$ in the $\mathrm{Bd} 21 \times \mathrm{Bd} 3-1$ RIL population. Presented 734 values are the means between the two sampled environments for each RIL. Arrows 735 correspond to the parental line means.

736 Figure 4 - Conditional QTL LOD plot for $\delta^{13} \mathrm{C}$ as estimated using stepwise regression in $\mathrm{r} / \mathrm{qtl}$. 737 Mapped $\delta^{13} \mathrm{C}$ values are the mean between the two sampled environments. Named LOD 738 peaks are significant at $\alpha=0.1$, as determined by permutation testing. Only chromosomes 739 with a significant QTL association are shown. Details on effect size for each QTL are $740 \quad$ presented in Table 1.

741 Figure 5 - Epistatic interactions between $\delta^{13} \mathrm{C}$ QTL detected on linkage group 2 (delta-2.2) and 742 linkage group 5 (delta-5) detected in stepwise regression genome scans. Mapped $\delta^{13} \mathrm{C}$ values 743 are the mean between the two sampled environments. Vertical bars indicate one standard 744 error of the mean.

745 Figure 6 - Reaction norm plot showing plastic leaf carbon content controlled by a locus on 746 linkage group 1 (leafCdiff-1) detected in stepwise regression genome scans. "Control" 747 treatment plants received $100 \mathrm{~mL}$ of water every second day while "Dry" treatment plants 748 received $50 \mathrm{~mL}$ of water every second day. Vertical bars indicate one standard error of the 749 mean. 


\begin{tabular}{|c|c|c|c|c|c|c|}
\hline QTL & Trait & Chrom. & $\begin{array}{l}\text { Position }(\mathrm{cM}) \\
(1.5 \text { LOD CI) }\end{array}$ & Nearest marker & $\begin{array}{l}\text { Effect } 2 \mathrm{a} \\
\text { (s.e) }\end{array}$ & $\% \mathrm{~V}_{\mathrm{G}}$ \\
\hline Delta-2.1 & $\delta^{13} \mathrm{C}$ & 2 & $\begin{array}{l}162.5 \\
(160-166)\end{array}$ & BD3819_3 & $\begin{array}{l}-0.154 \\
(0.033)\end{array}$ & 9.3 \\
\hline Delta-2.2 & $\delta^{13} \mathrm{C}$ & 2 & $\begin{array}{l}187.1 \\
(182-191)\end{array}$ & BD0309_1 & $\begin{array}{l}-0.040 \\
(0.033)\end{array}$ & 11.9 \\
\hline Delta-3 & $\delta^{13} \mathrm{C}$ & 3 & $\begin{array}{l}120.0 \\
(104-125.9)\end{array}$ & BD3:21986377 & $\begin{array}{l}0.120 \\
(0.030)\end{array}$ & 6.9 \\
\hline Delta-5 & $\delta^{13} \mathrm{C}$ & 5 & $\begin{array}{l}75.0 \\
(70-78)\end{array}$ & BD0218_4 & $\begin{array}{l}0.139 \\
(0.030)\end{array}$ & 19.4 \\
\hline leafCdiff-1 & $\begin{array}{l}\text { Leaf C } \\
\text { Plasticity }\end{array}$ & 1 & $\begin{array}{l}176.0 \\
(156-187)\end{array}$ & BD0177_1 & $\begin{array}{l}-5.770 \\
(1.418)\end{array}$ & 10.0 \\
\hline Biomass-1 & $\begin{array}{l}\text { Total aerial } \\
\text { dry biomass }\end{array}$ & 1 & $\begin{array}{l}98 \\
(90-112)\end{array}$ & BD1:33081967 & $\begin{array}{l}0.062 \\
(0.017)\end{array}$ & 7.3 \\
\hline Biomass-2 & $\begin{array}{l}\text { Total aerial } \\
\text { dry biomass }\end{array}$ & 2 & $\begin{array}{l}89.9 \\
(83-114)\end{array}$ & BD0399_5 & $\begin{array}{l}0.066 \\
(0.017)\end{array}$ & 8.5 \\
\hline
\end{tabular}

Table 1. Results of QTL analyses in the Bd3-1 x Bd21 population using two-dimensional 755 genome scans. 
755

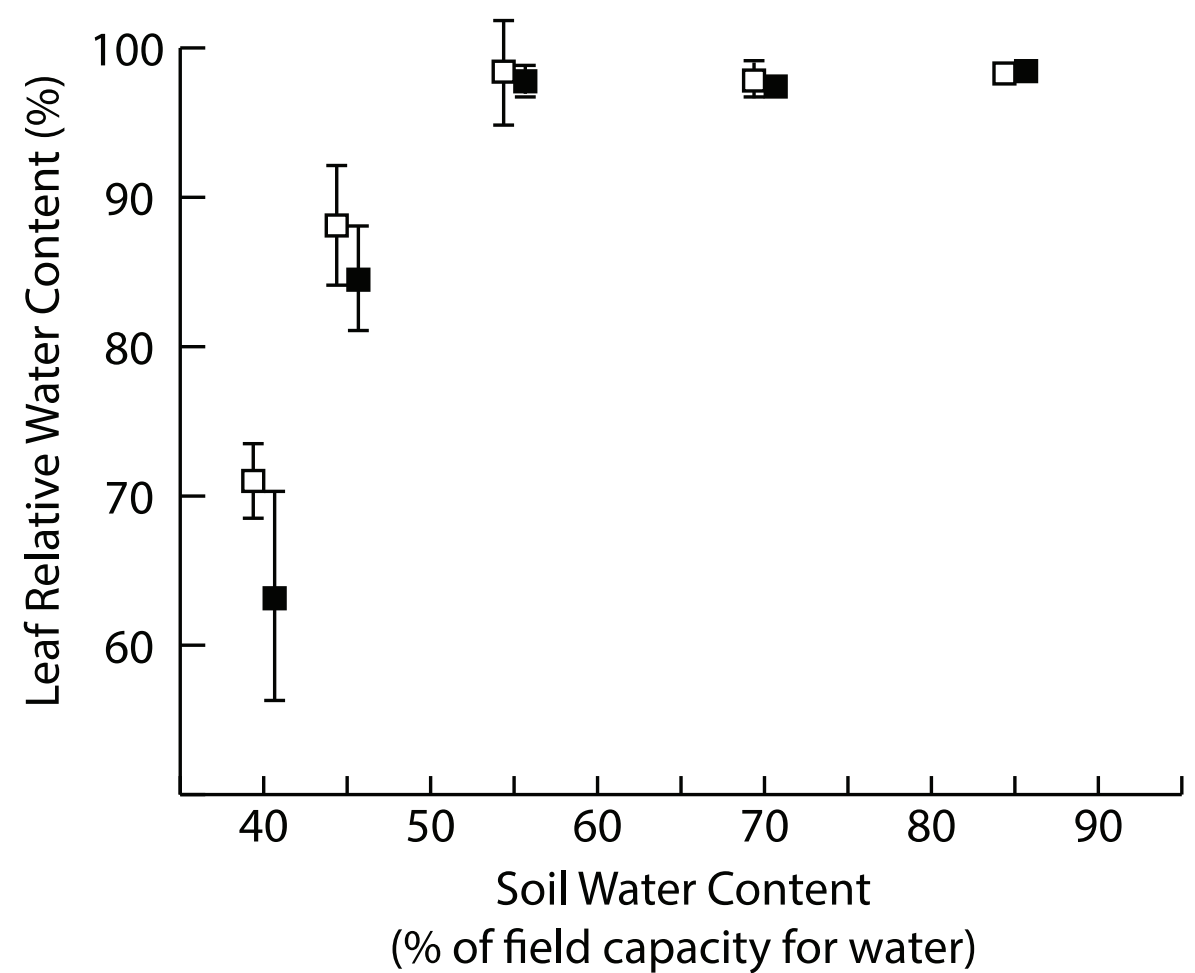

757 Figure 1

758 
Des Marais et al. 26

758
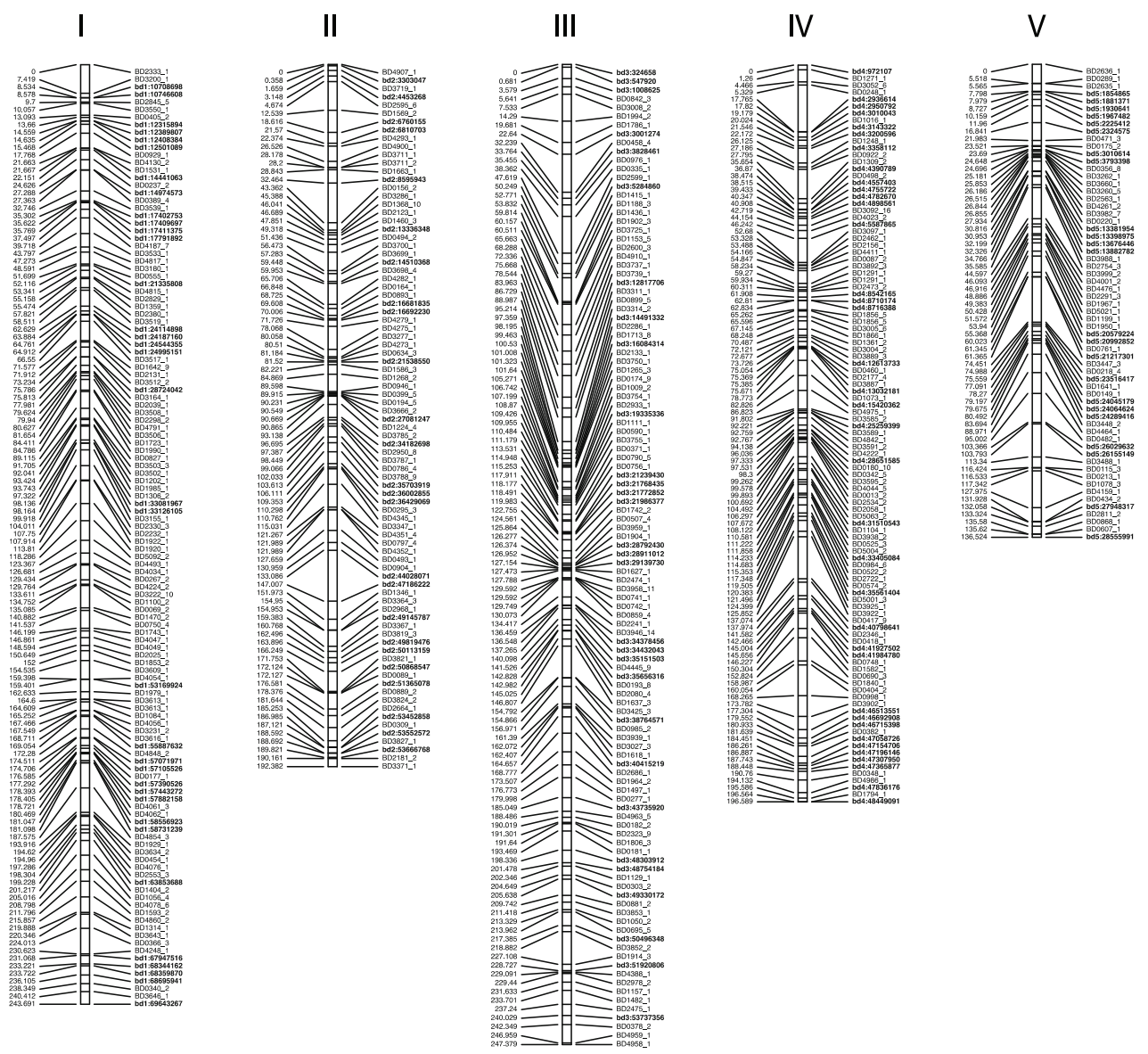

759

760

Figure 2

761 
Des Marais et al. 27

761

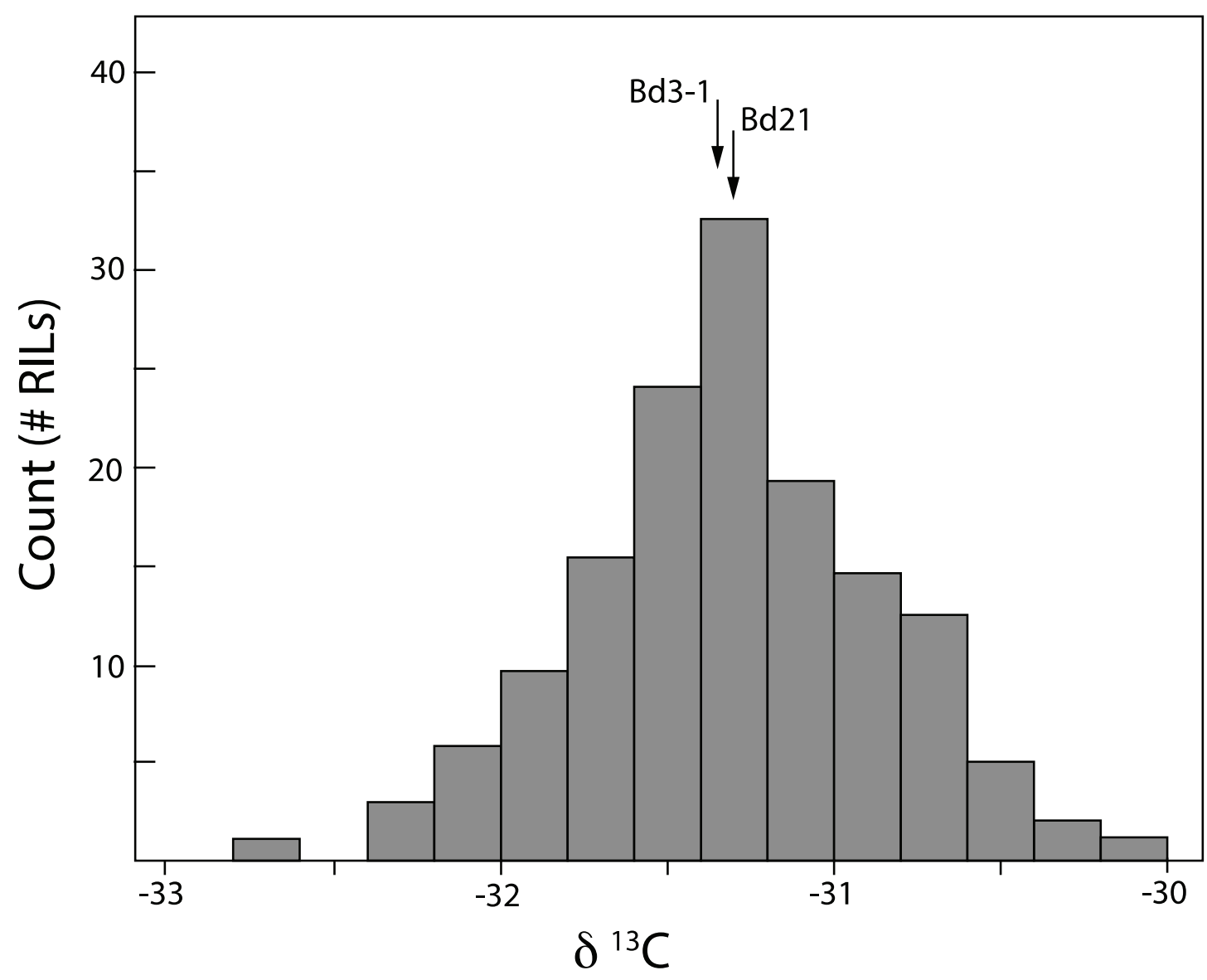

763 Figure 3

764 
Des Marais et al. 28

764

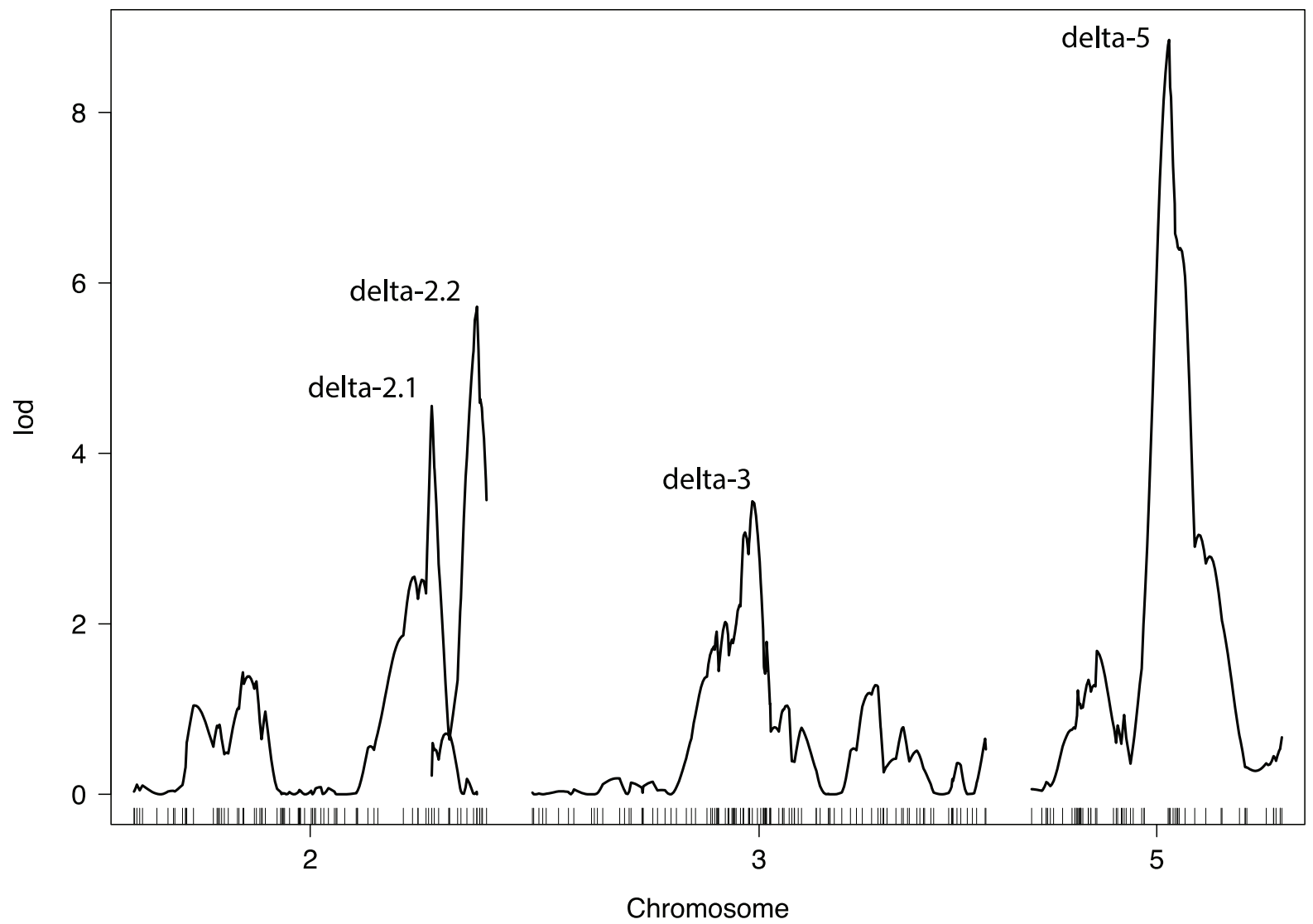

Figure 4 
Des Marais et al. 29

767

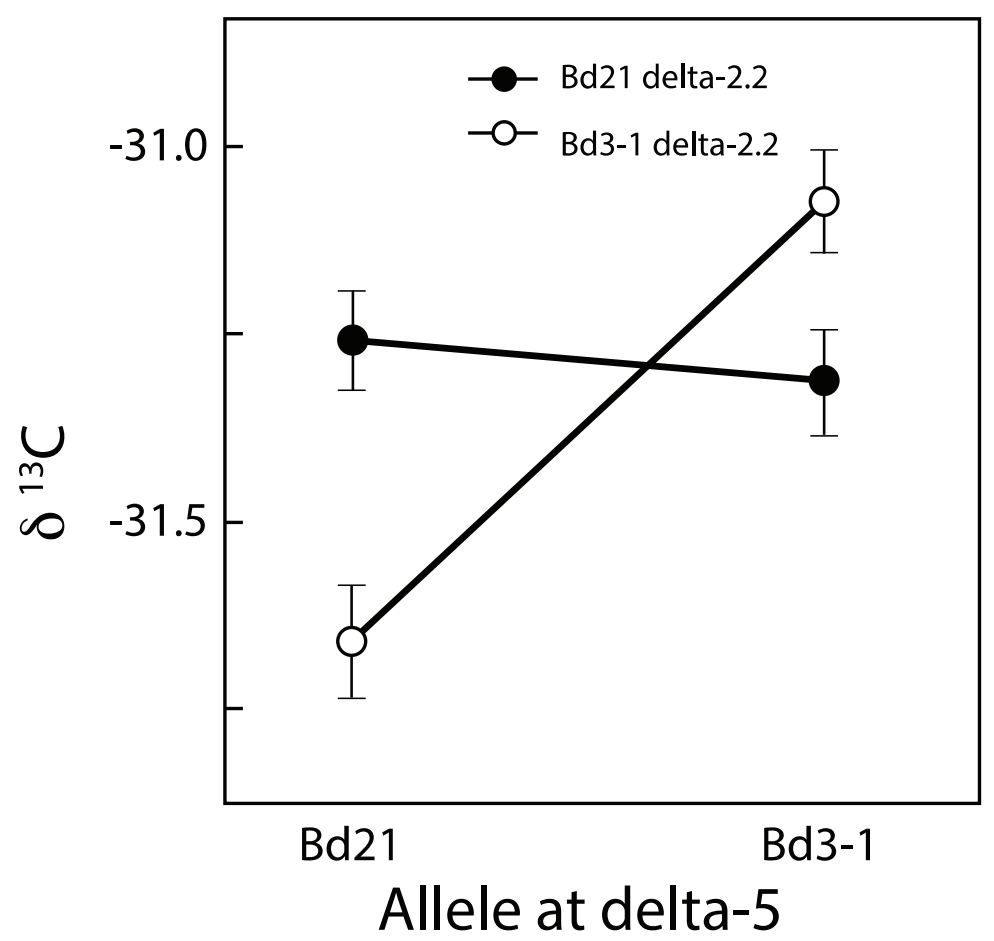

Figure 5

770 
Des Marais et al. 30

770

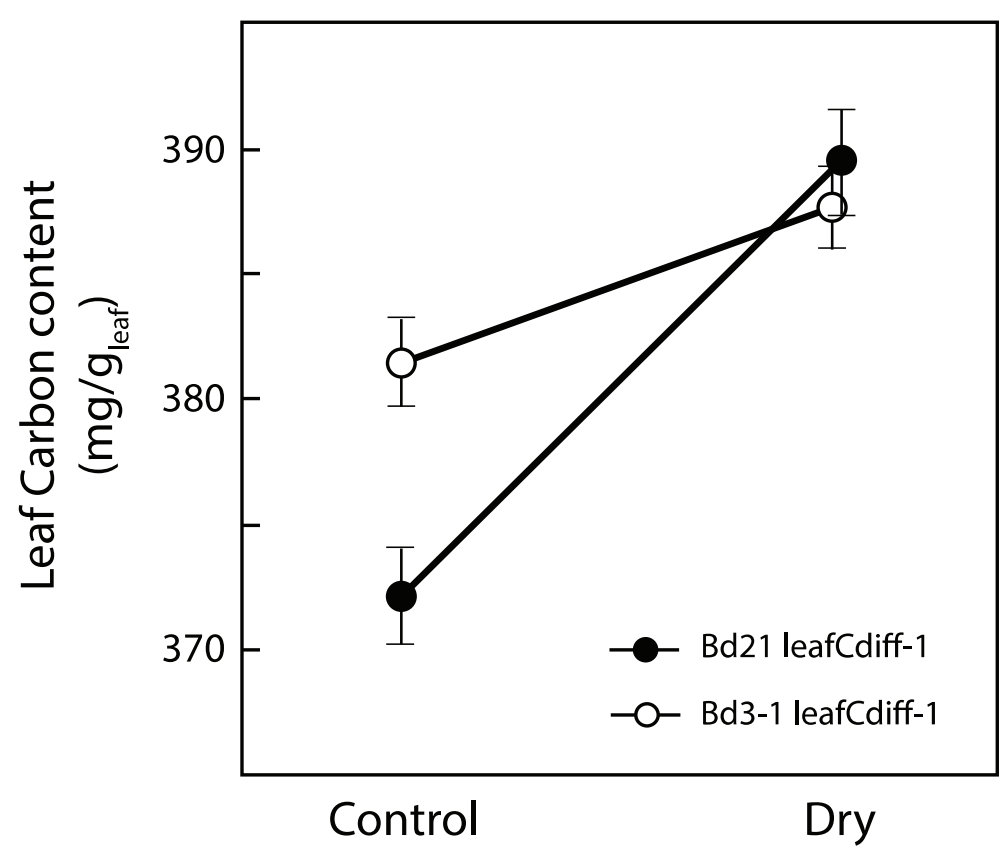

772 Figure 6

773

774

775 